\title{
Habitat-based predictive mapping of rockfish density and biomass off the central California coast
}

\author{
Lisa Wedding ${ }^{1,2, *}$, Mary M. Yoklavich ${ }^{1}$ \\ ${ }^{1}$ Fisheries Ecology Division, Southwest Fisheries Science Center, National Oceanic and Atmospheric Administration, \\ 110 Shaffer Rd., Santa Cruz, California 95060, USA \\ ${ }^{2}$ Center for Ocean Solutions, Stanford University, 99 Pacific Street, Suite 555E, Monterey, California 93940, USA
}

\begin{abstract}
Understanding the association between components of habitat and fish distribution and abundance is important in order to achieve accurate stock assessments. We developed generalized additive models (GAM) and spatially predictive maps of rockfish abundance at the individual species level using habitat descriptors collected from visual surveys and fine-scale bathymetry. We advanced beyond presence/absence and presence only models to create predictive maps of fish density $\left(100 \mathrm{~m}^{-2}\right)$ and biomass $\left(\mathrm{kg} 100 \mathrm{~m}^{-2}\right)$ for Sebastes rosaceus (rosy rockfish) and $S$. constellatus (starry rockfish), both common species in commercial and recreational fisheries along the central coast of California. Selected models included co-variables of seafloor depth, complexity, substratum type, and heterogeneity. Predicted density and biomass of both species were highest in areas of complex rock on the continental shelf off Points Lobos and Sur at 50-90 (S. rosaceus) and 80-120 m (S. constellatus) water depth. Our results will be useful both in stock assessments of these data-poor species as well as in allocation of fishing effort, catches, and other space-based management decisions.
\end{abstract}

KEY WORDS: Visual surveys · Rockfishes - Generalized additive model · Central California

\section{INTRODUCTION}

Pacific coast Sebastes spp. (rockfishes) are a wideranging and diverse genus comprising at least 65 species that occupy most benthic habitats from shallow estuaries and kelp forests to muddy slopes at $1500 \mathrm{~m}$ depth (Love et al. 2002). Several life-history characteristics (e.g. slow growth, longevity sometimes $>100 \mathrm{yr}$, and delayed sexual maturity; Love et al. 2002) make most rockfish populations particularly vulnerable to high levels of fishing mortality. Approximately 40 species of rockfishes dominate deep-water fish assemblages in rocky habitats off California (Love \& Yoklavich 2006) and support valuable recreational and commercial fisheries that have been ongoing since the mid-1800s (Love 2006, Miller et al. 2014).

Populations of 6 species of rockfishes currently are being rebuilt after having been classified as

\footnotetext{
${ }^{*}$ Corresponding author: lwedding@stanford.edu
}

overfished by the National Marine Fisheries Service and Pacific Fishery Management Council (PFMC 2011). Rebuilding plans for overfished stocks are required in accordance with the US Sustainable Fisheries Act of 1998 (16 U.S.C. § 1854[e][2]), which highlights the importance of identifying the physical and biological habitat factors that influence the distribution and abundance of these fish species. A number of management actions have been taken to support the rebuilding of rockfish stocks, including time and area closures, fishing gear modifications, minimum stock size thresholds, and catch and size limits. Timely stock assessments are needed to support these management actions (Punt \& Ralston 2007, Ralston \& MacFarlane 2010), yet only 25 of the 59 federally managed rockfish species have been assessed (www.pcouncil.org/groundfish/stockassessments/).

() The authors 2015. Open Access under Creative Commons by Attribution Licence. Use, distribution and reproduction are unrestricted. Authors and original publication must be credited. 
Sedentary rockfishes living in heterogeneous, high-relief, rocky habitats are difficult to appraise accurately with conventional methods such as bottom-trawl gear. Fishery-independent surveys using non-extractive visual methods (e.g. from a submersible) are an effective means to assess and monitor stocks in rebuilding status and provide the opportunity to examine fish-habitat relationships at finer spatial scales ( 1 to $5 \mathrm{~m}$ ) than course (1 to $2 \mathrm{~km}$ ) benthic trawl gear (Anderson et al. 2009). For instance, habitat-specific estimates of density and biomass from visual surveys (Yoklavich et al. 2007) are used in current stock assessments of S. levis (cowcod).

Advances in seafloor mapping technologies, coupled with recent developments in modeling approaches, support robust predictions of fish assemblages (Moore et al. 2010, Pittman \& Brown 2011) and individual species (Young et al. 2010). Rockfishes demonstrate strong affinities to high- and lowrelief rocky substrata at specific depths (Yoklavich et al. 2000, Laidig et al. 2009, Love et al. 2009). Additionally, habitat complexity and position relative to the surrounding seabed have further informed spatially predictive models of rockfish distributions (Iampietro et al. 2008, Young et al. 2010). Predicting rockfish density and biomass at the individual species level, based on a variety of seafloor substratum variables, provides important information to improve the assessment of fish stocks in rebuilding status.

In this study, we developed spatially predictive models and maps of abundance for $S$. rosaceus (rosy rockfish) and $S$. constellatus (starry rockfish), typical members of the mid-shelf fish assemblage on rocky substrata off central California, USA (Love \& Yoklavich 2006). Rosy rockfish geographically range from the Strait of Juan de Fuca (Washington, USA) to southern Baja California, Mexico, but are most abundant from Cordell Bank off northern California to northern Baja California (Love 2011). Starry rockfish range from northern California to southern Baja California, and are relatively abundant from central California to southern Baja California. Juveniles and adults of both species co-occur in the same depths and substratum types. These are medium-size, mostly solitary species (maximum length 36 and $46 \mathrm{~cm}$ for rosy and starry rockfish, respectively), and moderately long lived (likely maximum age at least $40^{1}$ and 32 yr for rosy and starry rockfish, respec-

${ }^{1}$ Pers. comm., D. Pearson, Fisheries Ecology Division, Southwest Fisheries Science Center, NOAA, 110 Shaffer Rd., Santa Cruz, CA 95060, USA. tively) (Love et al. 2002). Both species are commonly encountered in commercial and recreational fisheries along the central coast of California (Love et al. 2002) and yet are considered to be data-poor stocks (i.e. having only catch data available for assessments; Dick \& MacCall 2010).

Our overall goal was to model and map fish density $\left(100 \mathrm{~m}^{-2}\right)$ and biomass $\left(\mathrm{kg} 100 \mathrm{~m}^{-2}\right)$ of $S$. rosaceus and $S$. constellatus based on a variety of seafloor descriptors. The recent availability of detailed and accurate maps of substratum complexity from multibeam-acoustic surveys of the seafloor within California's territorial waters (i.e. those data coming from the California Seafloor Mapping Program) made it possible to produce regional maps of predicted density and biomass at scales that are ecologically relevant to these species. These results will improve our understanding of habitat variables that influence the spatial distribution of these species, advance their stock assessments, and find application in the newly developed California Current integrated ecosystem assessment (Levin \& Schwing 2011).

\section{MATERIALS AND METHODS}

\section{Study area}

Our study area was located largely within state waters (3 nautical miles) off central California, USA, including the southern portion of Monterey Bay, Point Lobos, Point Sur, and Big Creek on the Big Sur coast (Fig. 1). We focused our research efforts in depths from 35 to $150 \mathrm{~m}$, bracketing the depths of occurrence for the 2 species of interest (Sebastes rosaceus and $S$. constellatus), and across a range of rocky habitats including extensive rock and boulder fields (e.g. off the Point Lobos and Point Sur headlands), isolated rocky outcrops and pinnacles that can be several meters high and surrounded by flat, sandy seafloor, and on rock talus piles, scarps, and ledges in the heads of submarine canyons along the Big Sur coast. Water is relatively cool and productive along this section of the coast because the California Current flows equatorward year round, and substantial upwelling of cold deep water occurs at the headlands, typically in spring and summer (Hickey 1998). Commercial and recreational fishing with various types of gear has been supported by the diverse habitats on the continental shelf and upper slope in this region for well over $60 \mathrm{yr}$ (Love et al. 2002). 


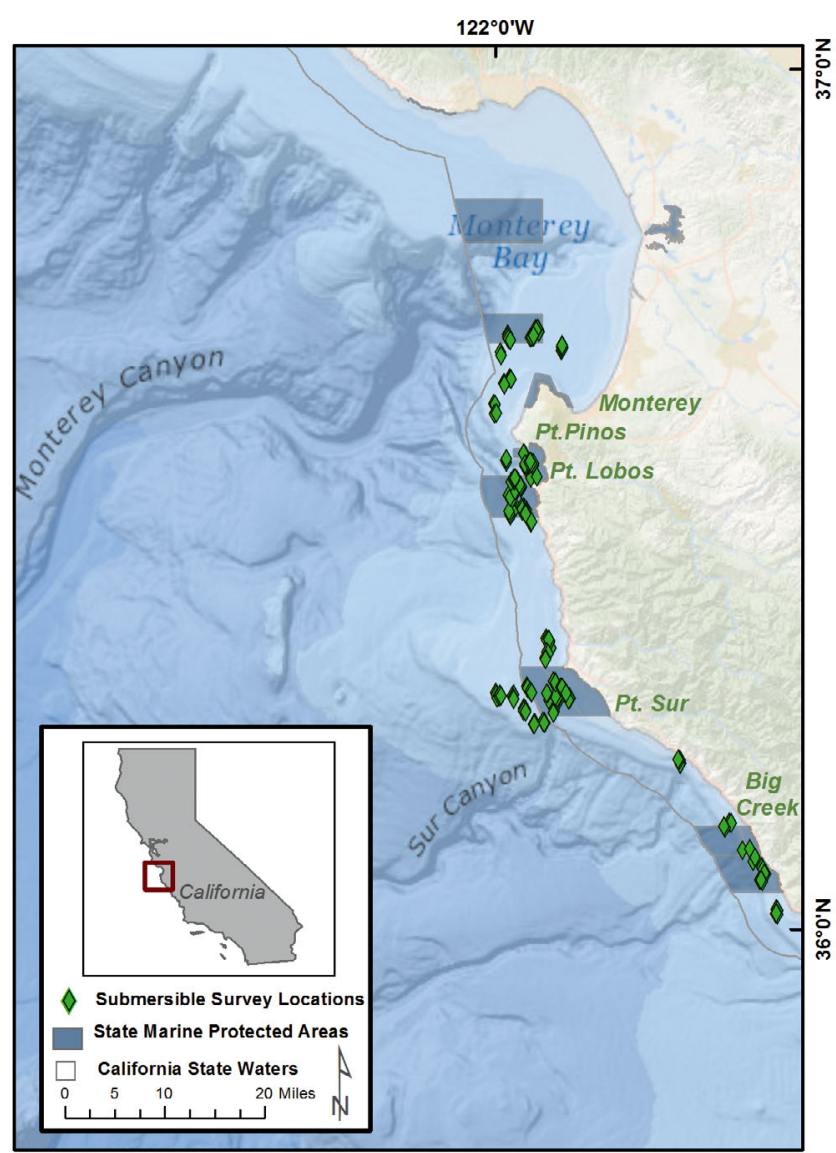

Fig. 1. Delta submersible survey locations in Monterey Bay and along the Big Sur coast, off central California, USA

\section{Data sets}

Visual surveys of demersal fishes and components of their habitats were conducted using a manned submersible (Delta) during daytime hours from September to November in 2007 and 2008 (see Yoklavich et al. 2000, 2002, 2007 for details on the Delta survey vehicle and methods). Dives were positioned randomly in areas of rocky substrata that were identified from maps of bathymetry (Monterey Bay Aquarium Research Institute Mapping Team, Monterey Bay Multibeam Survey; Seafloor Mapping Lab, California State University Monterey Bay [SFML-CSUMB]) and from interpreted seafloor habitats (Yoklavich et al. 1997, Eittreim et al. 2000). Surveys were conducted by traversing haphazardly across substratum types and depth gradients within designated rocky habitats. Soft sediment was not specifically targeted, but was surveyed along with rocky substrata on the quantitative sample transects. The same general areas were surveyed in 2007 and 2008, but transects were not re-sampled from one year to the next. Sen- sors mounted on the outside of the submersible recorded time, depth (pressure), and altitude at $1 \mathrm{~s}$ intervals throughout each dive.

A total of 304 strip transects 2 m wide were conducted for $10 \mathrm{~min}$ each along the seafloor. A distance within $1 \mathrm{~m}$ of the seafloor and a speed of 0.5 to 1.0 knots were maintained during the transect surveys. The submersible's position was tracked at 1 to 3 s intervals using an ORE Trackpoint II ultra-short baseline (USBL) acoustic system (EdgeTech) and WINFROG software (v3.1; FUGRO). A scientific navigator aboard the support vessel directed the start of a transect once the submersible arrived at the predetermined target depth and location, and tracked the submersible in real time within ArcGIS relative to bathymetric maps. The length $(\mathrm{m})$ of each transect was estimated using a Doppler velocity log (DVL) (NavQuest 600 Micro) and ring-laser gyrocompass (CDL MiniRLG 2) attached to the outside of the submersible. Two video cameras (one outside and one inside the submersible) were used to visually document each transect.

A pilot operated the submersible while an experienced scientist identified, counted, and estimated total length ( $\mathrm{TL}, \mathrm{cm}$; using paired lasers spaced $20 \mathrm{~cm}$ apart) of all fishes within a transect. Fish density $\left(100 \mathrm{~m}^{-2}\right)$ and biomass $\left(\mathrm{kg} 100 \mathrm{~m}^{-2}\right)$ for Sebastes rosaceus and $S$. constellatus were calculated from each transect. To calculate biomass, TL of fish was converted to weight $(\mathrm{g})$ using $W=0.0052 \times \mathrm{TL}^{3.386}$ $(\mathrm{R}=0.98259)$ for $S$. rosaceus and $W=0.0097 \times \mathrm{TL}^{3.160}$ $(\mathrm{R}=0.97805)$ for $S$. constellatus (Love et al. 1990). The relationship between length and weight was identical for males and females for both species.

Seafloor substratum types (mud, sand, gravel, pebble, cobble, boulder, continuous flat rock, rock ridge and pinnacle top) were classified from the video of each transect, based on geological definitions detailed in Greene et al. (1999). Distinct habitat patches, with a minimum duration of $3 \mathrm{~s}$, were defined by assigning primary (at least $50 \%$ of the area viewed) and secondary ( $>20 \%$ of the area viewed) substratum types each time a change was noted along the transect.

The length of each patch was determined from the DVL measurements. Primary substrata were grouped based on levels of structural complexity (Table 1). Pinnacle top, rock, and flat rock were classified as high complexity or large structured hard substratum type (Lhard). Boulders, cobble, pebble, and gravel were classified as medium complexity hard substratum (Mhard). Sand and mud comprised a soft substratum group (Soft) of low complexity. 
Table 1. Habitat characterization groups from submersible survey video analysis

\begin{tabular}{|ll|}
\hline Habitat image & Habitat type and complexity \\
\hline & $\begin{array}{l}\text { Habitat code: Lhard } \\
\text { Habitat description: } \\
\text { pinnacle top, rock, flat rock } \\
\text { Level of complexity: high }\end{array}$ \\
& $\begin{array}{l}\text { Habitat code: Mhard } \\
\text { Habitat description: } \\
\text { boulder, cobble, pebble, } \\
\text { gravel } \\
\text { Level of complexity: medium }\end{array}$ \\
& $\begin{array}{l}\text { Habitat code: Soft } \\
\text { Habitat description: } \\
\text { sand and mud } \\
\text { Level of complexity: low }\end{array}$ \\
\hline
\end{tabular}

An entire transect was characterized as a weighted sum of the patch substrata (O'Farrell et al. 2009). For substratum type $b$ ( $b \in$ Lhard, Mhard, Soft), in transect $t$, the numerical value describing that substratum's contribution $(S)$ was computed as:

$$
\mathrm{S}_{b, t}=\sum_{P}\left[S_{b, t, p} \times \frac{L_{t, p}}{\sum_{P} L_{t, p}}\right]
$$

where $L_{t, p}$ represents the length of patch $p$ in transect $t$. The resulting transect length-weighted habitat value characterized the 3 main substratum types (e.g. Lhard, Mhard, Soft) for each transect. This value, ranging from 0 (low complexity) to 0.7 (high complexity), was used as a metric of habitat complexity for each visual transect. Habitat heterogeneity was estimated as number of habitat patches per transect (Table 2).
Following our visual surveys, high-resolution multibeam data were collected throughout the entire study area by the California Seafloor Mapping Program (http://walrus.wr.usgs.gov/mapping/csmp). A $5 \mathrm{~m}$ resolution bathymetric Digital Elevation Model (DEM) and a derived Rough/Smooth classification of the seafloor were provided in grid format. Slope-ofslope (i.e. habitat complexity) was derived from the bathymetric grids using the ArcGIS Spatial Analyst extension (ESRI) slope function to obtain the rate of change of slope. Bathymetric position index (BPI) was calculated using the Benthic Terrain Modeler extension in ArcGIS. BPI is a second order derivative of the multibeam bathymetry data and characterizes a pixel in the bathymetric DEM as a positive (e.g. pinnacle top) or negative (e.g. canyon) feature of the surrounding seascape (Lundblad et al. 2006, Young et al. 2010). BPI grid creation and classification was applied using a scales of analysis at 5 pixel $(25 \mathrm{~m})$ and 50 pixel $(250 \mathrm{~m})$ annulus thickness for fine and broad respectively. Finally, the covariates were extracted for each transect using a $100 \mathrm{~m}$ radius moving window analysis in GIS.

\section{Statistical analysis}

Predictive models of fish density $\left(100 \mathrm{~m}^{-2}\right)$ and biomass $\left(\mathrm{kg} 100 \mathrm{~m}^{-2}\right)$ of Sebastes rosaceus and S. constellatus were developed using generalized additive models (GAM; Pinheiro \& Bates 2009, Zuur et al. 2009). These species are known to occur at specific depths and on distinct substratum types (Love et al. 2002); we used the flexible GAM to accommodate the expected non-linear responses of both species to our co-variates. Two sets of models were developed: (1) models based on the co-variables depth, a transect length-weighted value for the 3 substratum groups (i.e. Lhard, Mhard, Soft), and habitat heterogeneity, which were collected during the visual surveys, and measures of seafloor roughness, habitat

Table 2. Environmental co-variables collected during visual surveys and used in generalized additive models (GAMs) of rockfish density and biomass

\begin{tabular}{|c|c|c|c|c|c|}
\hline Co-variable & Description & Units & Source & Range & Mean (SD) \\
\hline Depth & Depth at start of transect & meters & Submersible sensor & $25-315$ & $137.4(83.1)$ \\
\hline Lhard* & Pinnacle top, rock, flat rock & length-weighted habitat value & $\mathrm{S}_{b, t}=\sum_{P}\left[S_{b, t, p} \times L_{t, p} / \sum_{P} L_{t, p}\right]$ & $0-0.7$ & $0.4(0.2)$ \\
\hline Mhard $^{*}$ & Boulder, cobble, pebble, gravel & length-weighted habitat value & $\mathrm{S}_{b, t}=\sum_{P}\left[S_{b, t, p} \times L_{t, p} / \sum_{P} L_{t, p}\right]$ & $0-0.7$ & $0.1(0.1)$ \\
\hline $\begin{array}{l}\text { Habitat } \\
\text { heterogeneit }\end{array}$ & $\begin{array}{l}\text { Measure of seascape patchiness } \\
y\end{array}$ & \# habitat patches on transect line & Video analysis & $1-57$ & $18.2(9.8)$ \\
\hline
\end{tabular}


complexity, and BPI derived from the high-resolution multibeam bathymetry; and (2) models based only on the co-variables derived from the multibeam bathymetry. Calculations were computed using $\mathrm{R}$ software and the mgcv package (Wood 2004) with a Gaussian error distribution and an identity link. Data exploration followed protocols described by Zuur et al. (2010). Cleveland dotplots and boxplots were used to determine the presence of outliers. Collinearity was investigated between covariates using Pearson correlation coefficients, multi-panel scatterplots, and variance inflation factors (VIF) (Montgomery \& Peck 1992).

Akaike's information criterion $(\triangle \mathrm{AIC})$ and Akaike weights $\left(w_{i}\right)$ were used to select the most parsimonious models among all possible covariate combinations (Burnham \& Anderson 2002). We selected models based on lowest AIC values using the MuMIn package (Barto 2011) and models having $\triangle$ AIC $<2$ were combined using a weighted $\left(w_{i}\right)$ model average. We used $\mathrm{k}$ fold cross validation in which we split the data into equal sized parts and then iteratively used part of the data to fit the model and a different part to test it (Hastie et al. 2009). We repeated each $\mathrm{k}$-fold cross validation process 500 times and examined the distribution of coefficient of determination. Validation of the optimum model was accomplished by inspecting homogeneity (plotting residual vs fitted values) and independence (variogram of residuals and plotting residuals versus each covariate).

Spatially predictive mapping was conducted in ArcGIS 10.1 using the Marine Geospatial Ecology Tool (MGET; v0.8a48) (Roberts et al. 2010), which integrates ArcGIS with the R statistical package (R Development Core Team 2011). In MGET, the GAM tool was applied to derive spatially predictive rasters for rockfish density and biomass. Prior to predictive mapping of the data for this analysis, data were randomly split into 'test' (1/3) and 'training' (2/3) sets to assess map accuracy. The training data sets were used to create the predictive maps, and the test data sets were applied to evaluate map accuracy assessment using Kendall's $\tau$ and Spearman's $\rho$.

\section{RESULTS}

\section{Spatial patterns of rockfish density and biomass}

Sebastes rosaceus and S. constellatus density and biomass data were used in our modeling efforts based on a total of 304 transects covering $146000 \mathrm{~m}^{2}$ of seafloor that comprised $70 \%$ LHard (pinnacle top, rock, and flat rock), 15\% Mhard (boulder, cobble, pebble, and gravel), and 15\% Soft (sand and mud) substrata at depths of 35 to $150 \mathrm{~m}$. Average density for $S$. rosaceus and $S$. constellatus was 3.42 ( $\mathrm{SE}=$ $0.16)$ and $0.74(0.06)$ fish $100 \mathrm{~m}^{-2}$, respectively. On transects, the average biomass was $0.26 \mathrm{~kg} 100 \mathrm{~m}^{-2}$ $\left(\mathrm{SE}=0.01\right.$ ) for $S$. rosaceus, and $0.14 \mathrm{~kg} 100 \mathrm{~m}^{-2}(0.01)$ for $S$. constellatus. Density of both species was relatively high on transects at Carmel Canyon, Point Sur, and Sur Canyon sites (Figs. 2a \& 3a). Spatial pattern of $S$. rosaceus biomass was similar to that of density along the Central California coast, with higher biomass coincident with areas of greater habitat structural complexity off the Monterey Peninsula, Point Lobos, and Point Sur (Fig. 2d). There were several pockets of relatively high biomass of $S$. constellatus along the central Californian coast, from the Monterey Peninsula to Big Creek, the most southern reaches of our study area (Fig. 3d).

\section{Modeling of Sebastes rosaceus density and biomass}

The GAMs to predict fish density and biomass were based on habitat co-variables from in situ visual surveys and multibeam acoustic bathymetry.

The selected GAM to predict $S$. rosaceus density included depth and hard rock substrata with high and medium complexity $\left(w_{i}=0.99\right.$; Table 3$)$. This selected model accounted for $42 \%$ of the variability in $S$. rosaceus density and had a mean $\mathrm{R}^{2}=0.40$ for 500 runs of 10 -fold cross-validation. From response curves, S. rosaceus density increased with depth from 35 to $\sim 70 \mathrm{~m}$ and then declined relatively steeply in deeper waters (Fig. 4a). The response curves for transect length-weighted habitat values indicated a steady increase in predicted $S$. rosaceus density with increasing complexity for both large (pinnacle top and rock habitat, Fig. 4b) and medium-to-small substrata (boulder, cobble, pebble, gravel habitat, Fig. 4c).

The selected GAM to predict $S$. rosaceus biomass included depth, hard rock substrata with high and medium complexity, habitat heterogeneity (e.g. number of patches per transect), and BPI ( $w_{i}=0.81$; Table 3), and accounted for $46 \%$ of the biomass variability (mean $\mathrm{R}^{2}=0.42$ ). The response curves for depth and both transect length-weighted habitat values (Lhard and Mhard) revealed the same patterns as in the density response curves (Fig. $4 \mathrm{~d}-\mathrm{f}$ ). From the BPI response curve (Fig. 4g), biomass was lowest in canyons and depressions (negative values of BPI) and demonstrated an overall increase to high BPI 

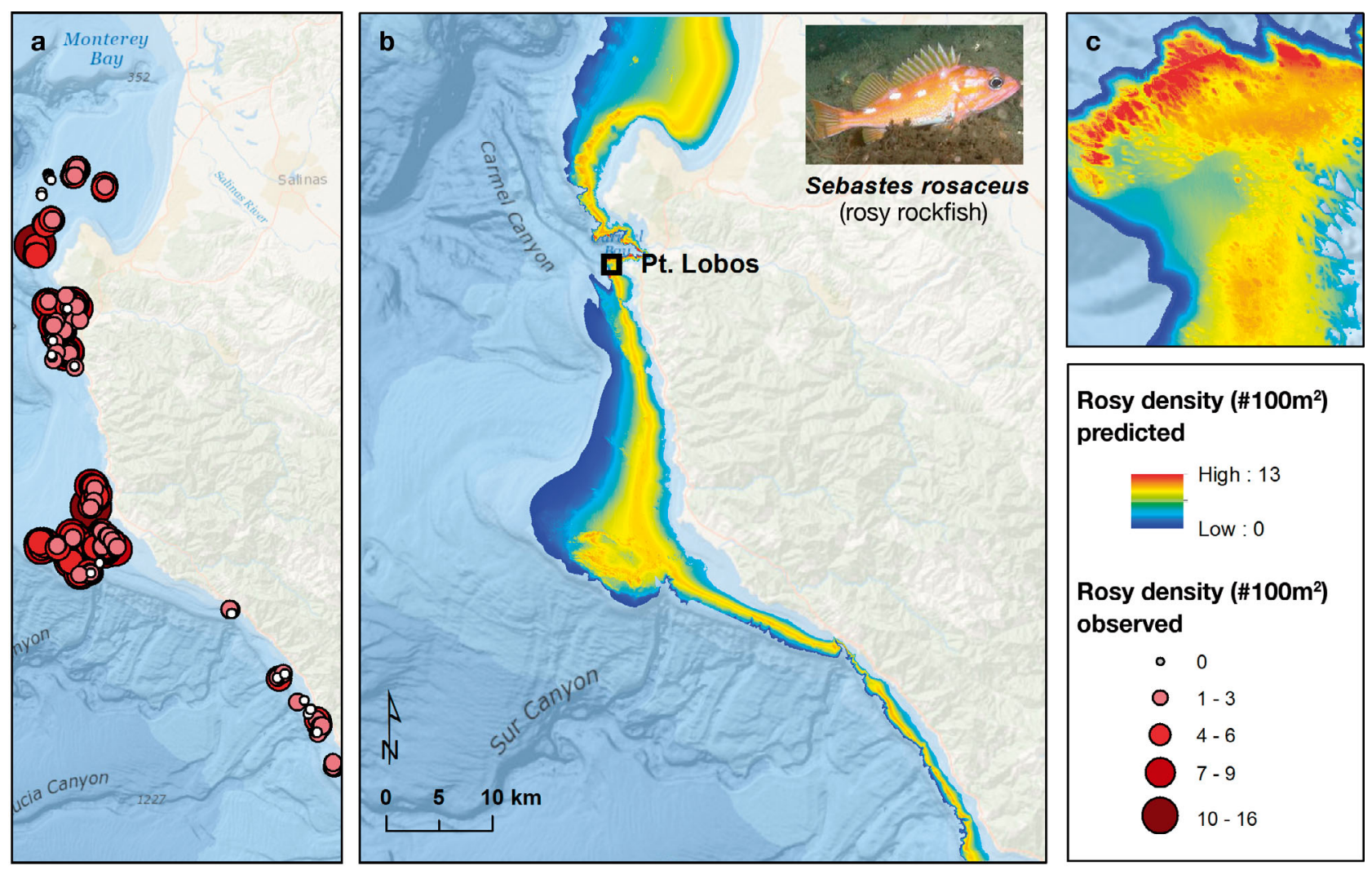

\section{Rosy density (\#100m²) predicted}

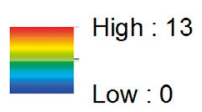

Rosy density (\#100m²) observed
$\circ 0$
○ 1 - 3
- 4-6
7-9
○ $10-16$
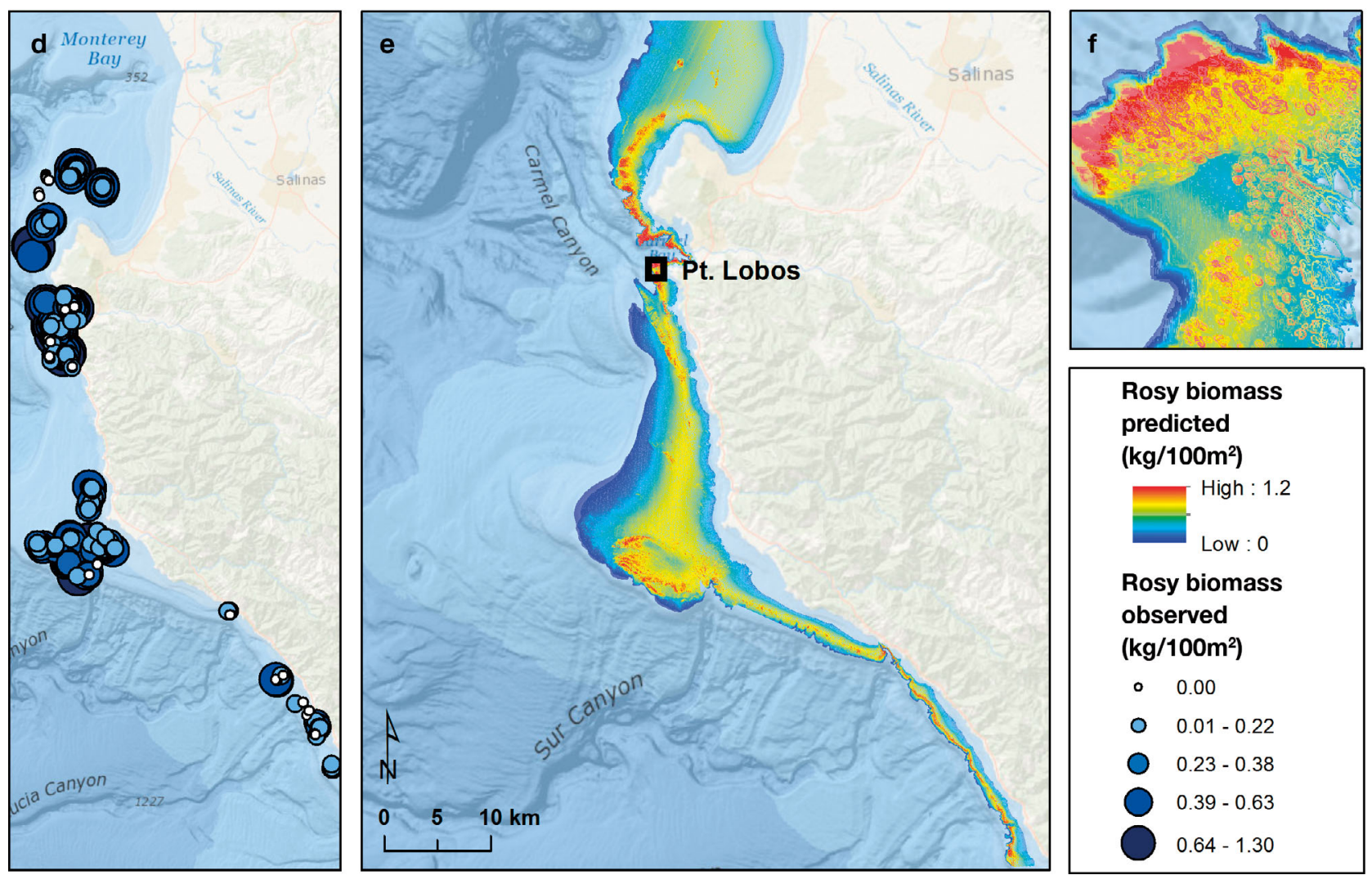

Rosy biomass predicted $\left(\mathrm{kg} / 100 \mathrm{~m}^{2}\right)$

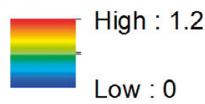

Rosy biomass observed (kg/100m²)
- 0.00
○ $\quad 0.01-0.22$
○ $0.23-0.38$
$0.39-0.63$
$0.64-1.30$

Fig. 2. Sebastes rosaceus. Density and biomass off central California, USA: (a) graduated dots of observed density; (b) predicted density throughout study area; (c) predicted density in enlarged map of area off Pt. Lobos; (d) graduated dots of observed biomass; (e) predicted biomass throughout study area; and (f) predicted biomass in enlarged map of area off Pt. Lobos 

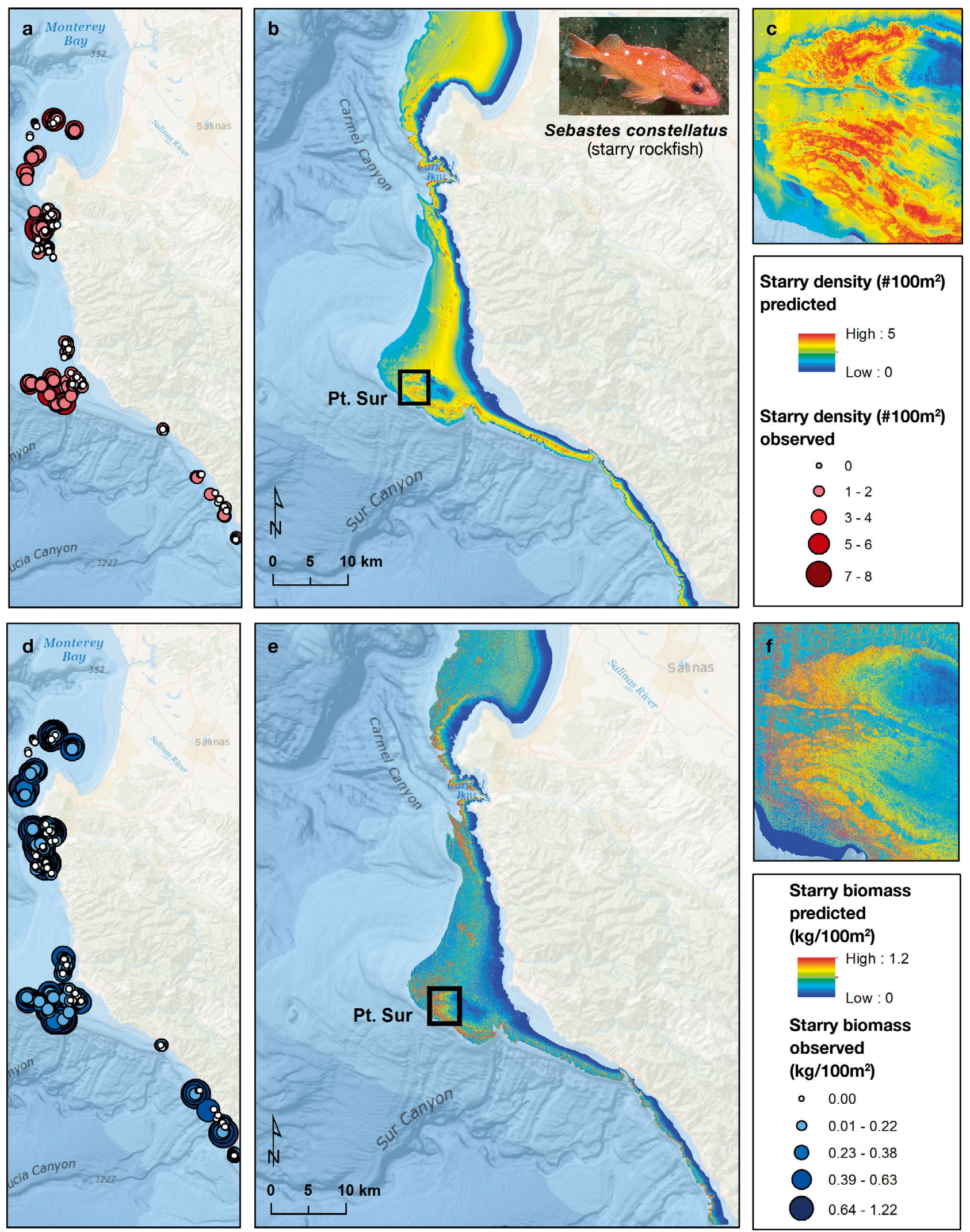

\section{Starry biomass predicted $\left(\mathrm{kg} / \mathbf{1 0 0 \mathrm { m } ^ { 2 } )}\right.$

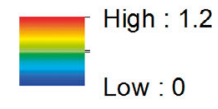

Starry biomass observed $\left(\mathrm{kg} / 100 \mathrm{~m}^{2}\right)$
- 0.00
○ $\quad 0.01-0.22$
O $0.23-0.38$
$0.39-0.63$
$0.64-1.22$

Fig. 3. Sebastes constellatus. Density and biomass off central California, USA: (a) graduated dots of observed density; (b) predicted density throughout the study area; (c) predicted density in enlarged map of area off Pt. Sur; (d) graduated dots of observed biomass; (e) predicted biomass throughout the study area; and (f) predicted biomass in enlarged map off Pt. Sur 
Table 3. Results of model selection to predict Sebastes rosaceus density and biomass off central California for 2 sets of models: (1) visual and bathymetry models and (2) bathymetry alone to support GIS-based predictive mapping. Models were ranked by Akaike's information criterion ( $\triangle \mathrm{AIC}$ ) and Akaike weights $\left(w_{i}\right)$. Models having $\triangle \mathrm{AIC}<2$ were combined using a weighted ( $w_{i}$ ) model average and are in bold. Lhard = high complexity or large structured hard substratum (pinnacle top, rock, and flat rock); Mhard = medium complexity hard substratum (boulders, cobble, pebble, and gravel); Soft = low complexity substratum (sand and mud)

\begin{tabular}{|c|c|c|c|}
\hline Model type & Model selection results & $\Delta \mathrm{AIC}$ & $w_{i}$ \\
\hline \multicolumn{4}{|c|}{ Models based on co-variables from both visual surveys and multibeam bathymetry } \\
\hline Density & S. rosaceus $\sim$ Depth + Lhard + Mhard & 0 & 0.99 \\
\hline Density & S. rosaceus $\sim$ BPI + Lhard + Mhard & 28.65 & 0.01 \\
\hline Biomass & S. rosaceus $\sim$ Depth + Lhard + Mhard + Habitat Heterogeneity + BPI & 0 & 0.81 \\
\hline Biomass & S. rosaceus $\sim$ Depth + Lhard + Mhard + BPI & 3.71 & 0.13 \\
\hline Biomass & S. rosaceus $\sim$ Depth + Lhard + Mhard + BPI + factor(Rough) & 5.39 & 0.01 \\
\hline \multicolumn{4}{|c|}{ Models based on co-variables derived from multibeam bathymetry } \\
\hline Density & S. rosaceus $\sim$ Depth + BPI & $\mathbf{0}$ & 0.45 \\
\hline Density & S. rosaceus $\sim$ Depth + BPI + factor(Rough) & 0.96 & 0.28 \\
\hline Density & S. rosaceus $\sim$ Depth & 2.12 & 0.15 \\
\hline Density & S. rosaceus $\sim$ Depth + factor(Rough) & 2.49 & 0.13 \\
\hline Biomass & S. rosaceus $\sim$ Depth + BPI + Habitat Complexity & $\mathbf{0}$ & 0.62 \\
\hline Biomass & S. rosaceus $\sim$ Depth + BPI + Habitat Complexity + factor(Rough) & 1.69 & 0.27 \\
\hline Biomass & S. rosaceus $\sim$ Depth + BPI + factor(Rough) & 4.41 & 0.07 \\
\hline
\end{tabular}

features (e.g. pinnacle tops). Biomass of $S$. rosaceus was highest in areas of $\sim 4$ to 6 habitat patches per $100 \mathrm{~m}^{2}$ (Fig. 4h), with declining biomass in areas of very low and high habitat heterogeneity (e.g. patchiness).

\section{Predictive maps of Sebastes rosaceus density and biomass}

The predictive maps for density and biomass were based solely on co-variates derived from acoustic multibeam bathymetry.

The selected GAM to create a predictive map of $S$. rosaceus density accounted for $33 \%$ of its density variability $\left(\mathrm{R}^{2}=0.32\right)$. The model was based on a weighted average of M1: S. rosaceus $\sim$ Depth + BPI, $w_{i}=0.45$ and M2: S. rosaceus $\sim$ Depth + BPI + factor(Rough), $w_{i}=0.28$ (Table 3). Model-averaged response curves for depth (Fig. 5a) and BPI (Fig. 5b) had greater density values for the rough substratum factor than for the smooth factor. In the response curve for BPI, density was lowest in canyons and depressions (similar to Fig. 4g), but also demonstrated distinct peaks in density associated with medium-relief habitat features (e.g. boulder fields) and high BPI features (e.g. pinnacle tops) (Fig. 5b).

The selected GAM for $S$. rosaceus biomass predictive map was a weighted model average M1: $S$. rosaceus $\sim$ Depth + BPI + Habitat Complexity, $w_{i}=$ 0.62 and M2: S. rosaceus $\sim$ Depth + BPI + Habitat
Complexity + factor (Rough), $w_{i}=0.27$ (Table 3). This model accounted for $38 \%$ of the biomass variability $\left(R^{2}=0.35\right)$. Response curves for depth (Fig. 5c), BPI (Fig. 5d), and habitat complexity (Fig. 5e) had greater biomass values for the rough substratum factor than for the smooth substratum factor. The response curve for predicted biomass versus depth was similar to that of the density curve, and demonstrated an increase in $S$. rosaceus biomass from 35 to $\sim 70 \mathrm{~m}$ and a decrease in biomass at greater depth ranges (Fig. 5c). In the response curve for BPI, S. rosaceus biomass followed the same pattern as the density curve and was lowest in canyons and depressions and was characterized by distinct peaks in biomass associated with low-relief habitat features (e.g. boulder fields) and high BPI features (e.g. pinnacle tops) (Fig. 5d). Habitat complexity was not important for modeling density, but for biomass this response curve indicated a sustained increase in $S$. rosaceus biomass with increasing complexity (Fig. 5e).

Predictive maps of $S$. rosaceus density (Fig. 2b) and biomass (Fig. 2e) were produced based on the average of the top 2 models by weight. Spatial patterns of biomass predicted across the study region were similar to that of density, with higher biomass coincident with areas of greater habitat structural complexity off the Monterey Peninsula, Point Lobos (Fig. 2c,f), and Point Sur. The highest predicted density and biomass of $S$. rosaceus rockfish were mapped on the continental shelf at 50 to $90 \mathrm{~m}$ water depth off Point Pinos and Point Sur. The predictive maps of $S$. rosaceus density 


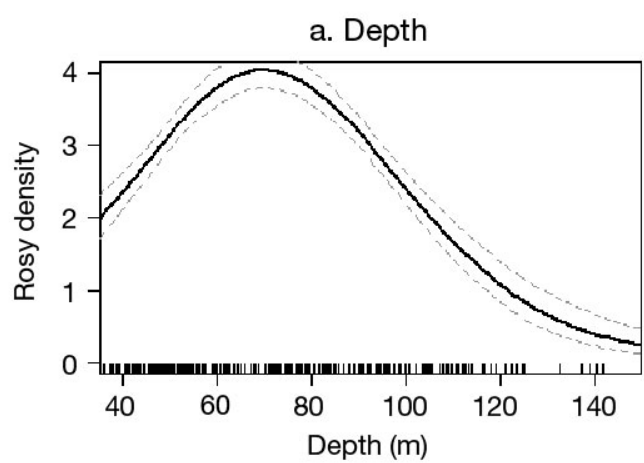

b. Pinnacle top and rock habitat

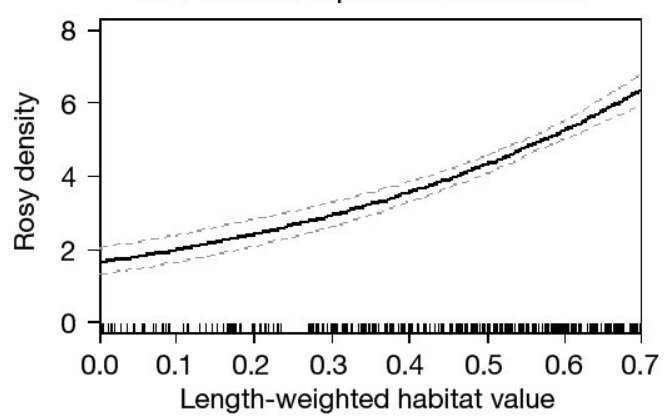

c. Boulder, cobble, pebble and gravel habitat

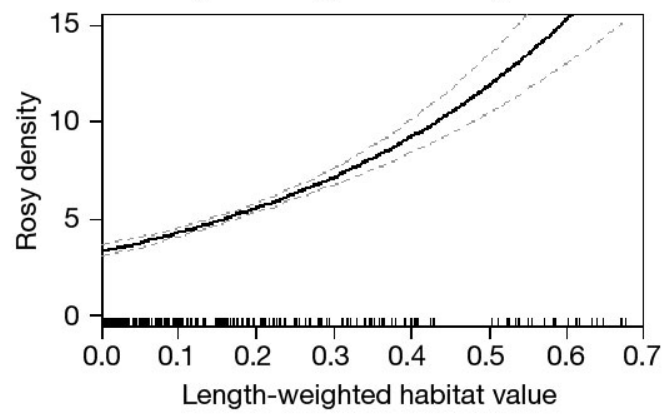

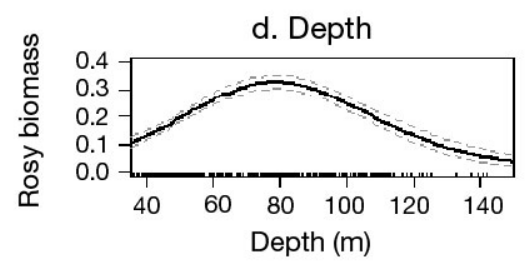

e. Pinnacle top and rock habitat

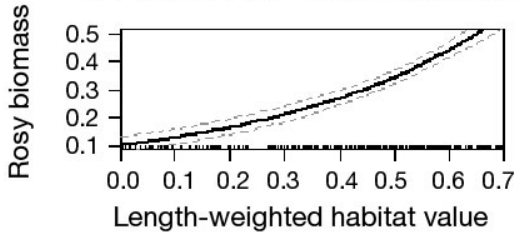

f. Boulder, cobble, pebble and gravel habitat

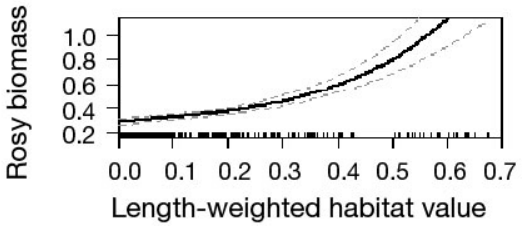

g. Bathymetric position index
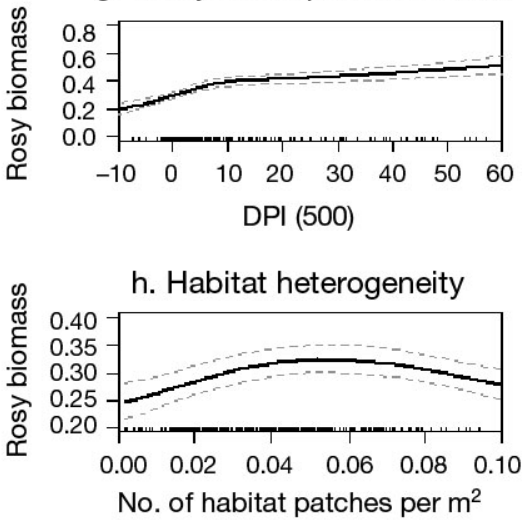

Fig. 4. Sebastes rosaceus. Response curves, based on habitat co-variables from visual surveys and acoustic multibeam bathymetry, for generalized additive model (GAM) predicted density versus (a) depth, (b) length-weighted habitat values in highrelief rock (Lhard) and (c) length-weighted habitat values in low-relief rock (Mhard); and GAM-predicted biomass versus (d) depth, (e) length-weighted habitat values in Lhard, (f) length-weighted habitat values in Mhard, (g) bathymetric position index $(\mathrm{BPI})$, and $(\mathrm{h})$ habitat heterogeneity. Solid lines = mean $( \pm 1 \mathrm{SE}$, dashed lines). Rug plots along the $x$-axis $=$ calibration data points

and biomass had an accuracy of Spearman's $\rho=0.63$ and 0.66 and Kendall's $\tau=0.46$ and 0.49 , respectively.

\section{Modeling of Sebastes constellatus density and biomass}

The selected GAM to predict $S$. constellatus density included depth and hard rock substrata with high and medium complexity $\left(w_{i}=0.99\right.$, Table 4$)$, and concluded in similar results to the $S$. rosaceus model. The model accounted for $43 \%$ of the variability in $S$. constellatus density $\left(\mathrm{R}^{2}=0.41\right)$. From response curves, $S$. constellatus occurred deeper than $S$. rosaceus, with relatively high densities in water depths $>80 \mathrm{~m}$ (Fig. 6a). Similar to $S$. rosaceus, the response curves for transect length-weighted habitat values indicated a steady increase in predicted $S$. constellatus density with increasing complexity for both large (pinnacle top and rock habitat, Fig. 6b) and medium-to-small rocky substrata (boulder, cobble, pebble, gravel habitat, Fig. 6c).

The model for $S$. constellatus biomass was a weighted average of depth, hard rock substrata 


\section{a. Depth}

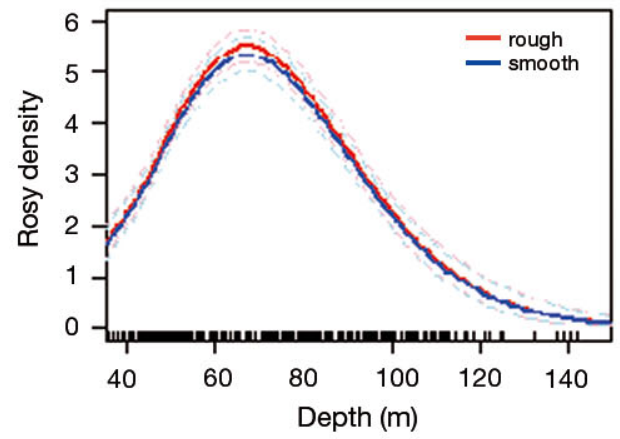

b. Bathymetric position index

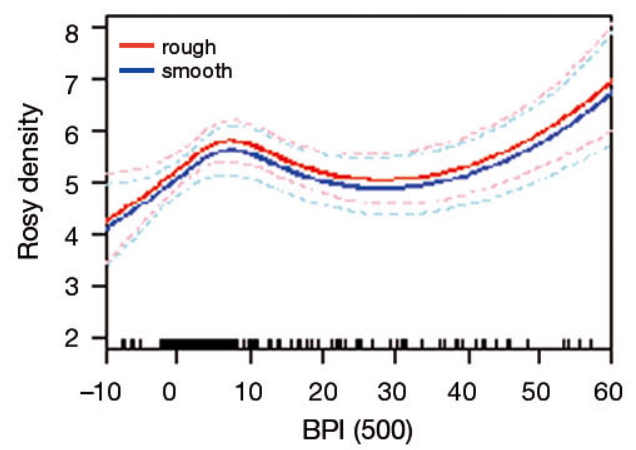

Fig. 5. Sebastes rosaceus. Response curves, based on habitat co-variables derived from acoustic multibeam bathymetric surveys, for generalized additive model (GAM) predicted density versus (a) depth and (b) bathymetric position index (BPI); and GAM-predicted biomass versus (c) depth, (d) BPI, and (e) habitat complexity with factor representing rough substratum (red lines) and smooth substratum (blue lines). Solid lines $=$ mean $( \pm 1 \mathrm{SE}$, dashed lines $)$. Rug plots along the $x$-axis $=$ calibration data points

with high and medium complexity, habitat heterogeneity, and BPI (Table 4), which accounted for $54 \%$ of its variability $\left(\mathrm{R}^{2}=0.40\right)$. The response curves for depth (Fig. 6d) and one transect lengthweighted habitat co-variable (i.e. Mhard; Fig. 6f) revealed the same patterns as in density response curves for this species. However, the response curve for the transect length-weighted habitat co-variable Lhard (Fig. 6e), which characterizes highly complex pinnacle top and rock, demonstrated an increase in biomass to an intermediate level followed by a steady increase at the highest complexity. As with $S$. rosaceus, BPI was not an important co-variate in the model that predicted density but was included in the selected GAM to predict biomass for S. constellatus; predicted biomass was lowest in submarine canyons and depressions (negative values of
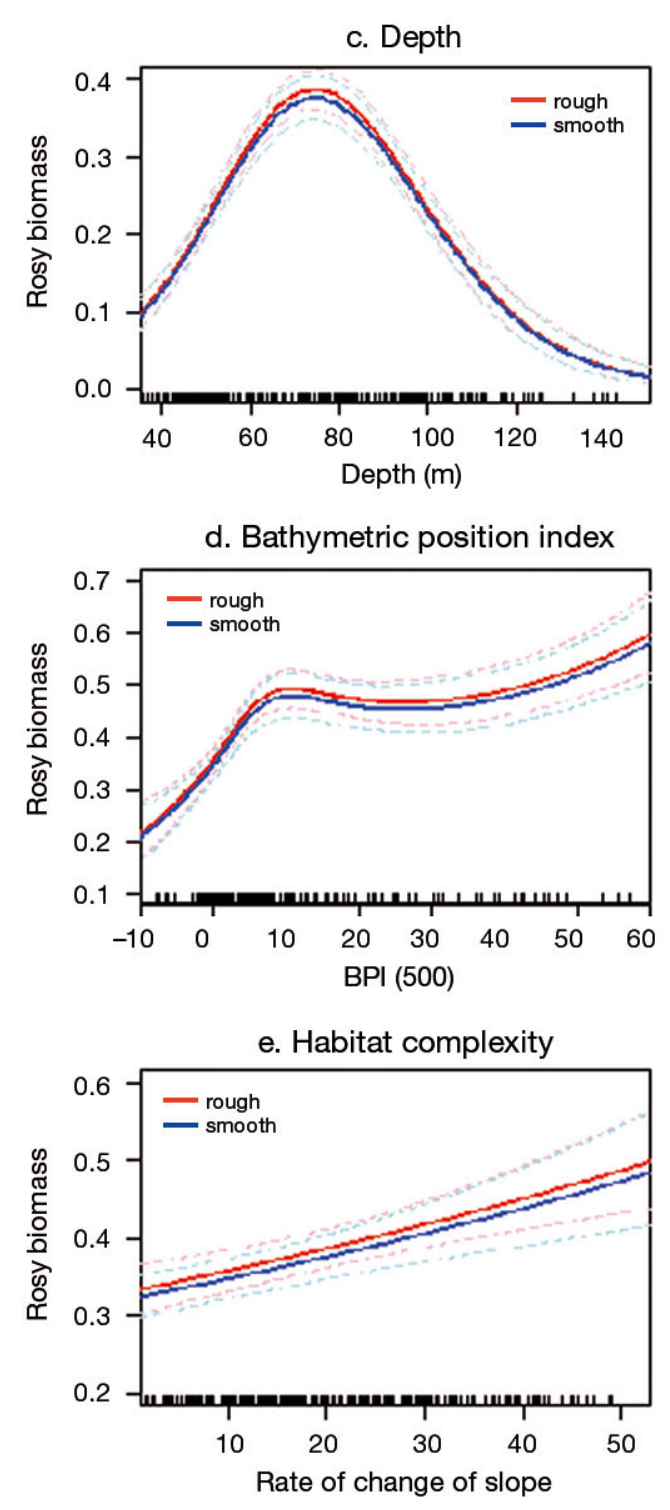

BPI) and peaked at low-relief habitat features (e.g. boulder fields, Fig. 6g). The response curve for habitat heterogeneity (Fig. 6h) demonstrated a different pattern than that of $S$. rosaceus biomass; predicted biomass of $S$. constellatus was greater in areas of more homogenous habitat (i.e. low numbers of habitat patches per $\mathrm{m}^{2}$ ).

\section{Predictive maps of Sebastes constellatus density and biomass}

The selected GAM to predict $S$. constellatus density was a weighted average of depth, BPI and rough substratum as a factor (Table 4). This model accounted for $29 \%$ of the variability in predicted S. constellatus density $\left(\mathrm{R}^{2}=0.27\right)$. Density of $S$. constellatus 
Table 4. Results of model selection to predict Sebastes constellatus density and biomass off central California for 2 sets of models: (1) visual and bathymetry models and (2) bathymetry alone to support GIS-based predictive mapping. Models are ranked by Akaike's information criterion $(\triangle \mathrm{AIC})$ and Akaike weights $\left(w_{i}\right)$. Models having $\Delta$ AIC $<2$ were combined using a weighted $\left(w_{i}\right)$ model average and are in bold. Lhard = high complexity or large structured hard substratum (pinnacle top, rock, and flat); Mhard = medium complexity hard substratum (boulders, cobble, pebble, and gravel); Soft $=$ low complexity substratum (sand and mud)

\begin{tabular}{|c|c|c|c|}
\hline Model type & Model selection results & $\Delta \mathrm{AIC}$ & $w_{i}$ \\
\hline \multicolumn{4}{|c|}{ Models based on co-variables from both visual surveys and multibeam bathymetry } \\
\hline Density & S. constellatus $\sim$ Depth +Lhard +Mhard & 0 & 0.99 \\
\hline Density & S. constellatus $\sim$ BPI +Lhard + Depth & 33.01 & 0.01 \\
\hline Biomass & S. constellatus $\sim$ Depth + Lhard +Mhard+ Habitat Heterogeneity + BPI & $\mathbf{0}$ & 0.60 \\
\hline Biomass & S. constellatus $\sim$ Depth +Lhard +Mhard + BPI & 1.48 & 0.29 \\
\hline Biomass & S. constellatus $\sim$ Depth +Lhard +Mhard + BPI + factor(Rough) & 3.45 & 0.10 \\
\hline \multicolumn{4}{|c|}{ Models based on co-variables derived from multibeam bathymetry } \\
\hline Density & S. constellatus $\sim$ Depth + BPI & $\mathbf{0}$ & 0.72 \\
\hline Density & S. constellatus $\sim$ Depth + BPI + factor(Rough) & 1.94 & 0.27 \\
\hline Density & S. constellatus $\sim$ Depth & 23.14 & 0.01 \\
\hline Biomass & S. constellatus $\sim$ Depth + BPI + Habitat Complexity & $\mathbf{0}$ & 0.54 \\
\hline Biomass & S. constellatus $\sim$ Depth + BPI + Habitat Complexity + factor(Rough) & 0.36 & 0.45 \\
\hline Biomass & S. constellatus $\sim$ Depth + Habitat Complexity & 7.71 & 0.01 \\
\hline
\end{tabular}

peaked at 70 to $90 \mathrm{~m}$ in the response curves for depth of both substratum types (Fig. 7a). The response curve for BPI indicated that $S$. constellatus density was lowest in canyons and depressions followed by a steep increase to relatively low positive BPI values that are associated with fine-scale habitat features such as boulder or rocky substrata at higher elevation relative to surrounding seascape (Fig. 7b). Density increased even more at the highest BPI values, indicating an association of $S$. constellatus with pinnacle tops.

The selected GAM for $S$. constellatus biomass was a weighted average of depth, BPI, habitat complexity, and rough substratum as a factor (Table 4). This model accounted for $32 \%$ of the variability in S. constellatus density $\left(\mathrm{R}^{2}=0.23\right)$. From response curves of co-variates depth (Fig. 7c), BPI (Fig. 7d), and habitat complexity (Fig. 7e), S. constellatus biomass was greater for the rough substratum factor than for the smooth factor. Peak biomass of $S$. constellatus was predicted at deeper depth (i.e. $\sim 100 \mathrm{~m}$ ) than that of peak density $(\sim 80 \mathrm{~m})$. The response curve for BPI indicated that $S$. constellatus biomass was lowest in canyons and depressions followed by a sharp peak associated with fine-scale habitat features that rise slightly above the surrounding seascape (Fig. 7d). The habitat complexity response curve indicated an increase in $S$. constellatus biomass with increasing habitat complexity.

The accuracies of the predictive maps of $S$. constellatus density and biomass were characterized by
Spearman's $\rho=0.36$ and 0.63 and Kendall's $\tau=0.53$ and 0.46 , respectively. Spatial patterns of predicted biomass of $S$. constellatus were highest in areas of complex rock off Point Lobos (Fig. 3e) and Point Sur (Fig. 3e,f); these areas were also associated with high predicted biomass of $S$. rosaceus.

\section{DISCUSSION}

Until recently, predictive habitat-based models and maps of demersal marine fish distribution had been largely developed from presence/absence or presence-only fish data (Iampietro et al. 2008, Young et al. 2010). In this paper, we attempt to advance beyond presence/absence and presence only models to develop predictive regional maps of rockfish density and biomass at the individual species level in a temperate ecosystem. There have been a number of spatially predictive mapping and modeling studies in tropical ecosystems. Costa et al. (2014) integrated habitat data from acoustic sensors (i.e. splitbeam and multibeam echosounders) in the US Virgin Islands to predict fish density, and found the model performed best at larger body sizes $(\geq 29 \mathrm{~cm})$ to identify fish aggregations and help coastal managers prioritize areas of higher conservation value. Pittman \& Brown (2011) similarly developed predictive maps for several key fish species associated with Caribbean coral reef seascapes and found that habitat complexity derived from Light Detection and Ranging Data 


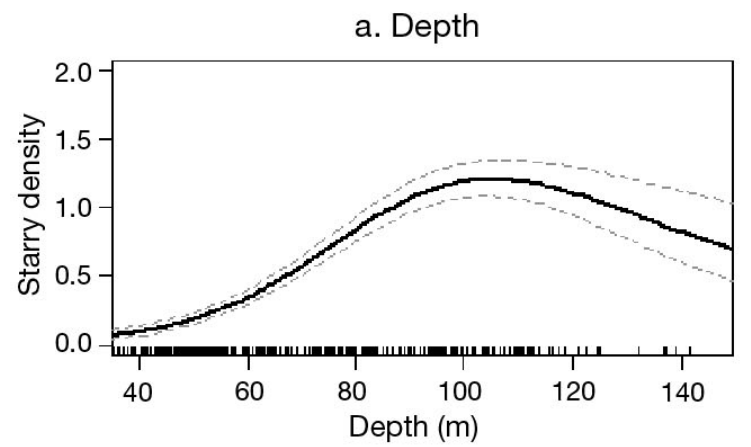

b. Pinnacle top and rock habitat

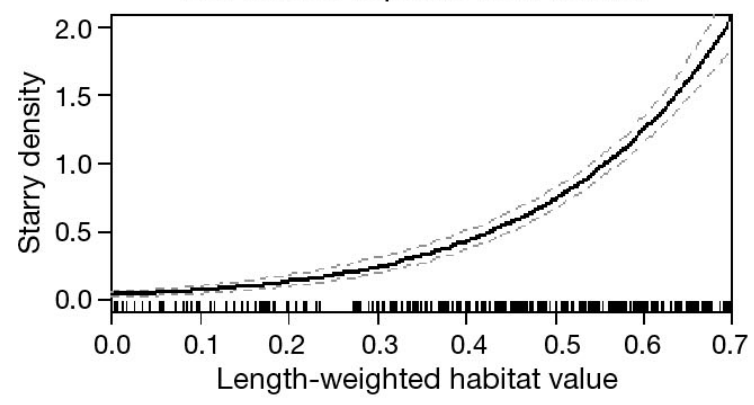

c. Boulder, cobble, pebble and gravel habitat

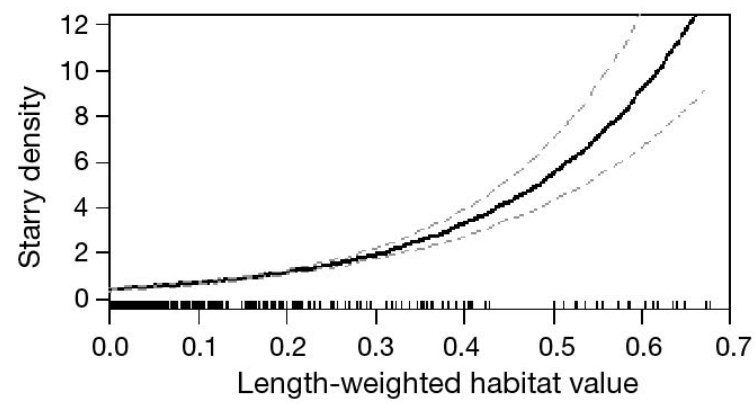

d. Depth

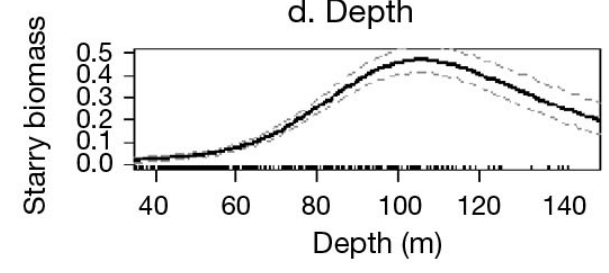

e. Pinnacle top and rock habitat

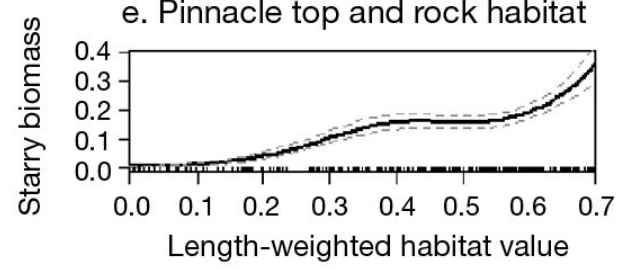

f. Boulder, cobble, pebble and gravel habitat
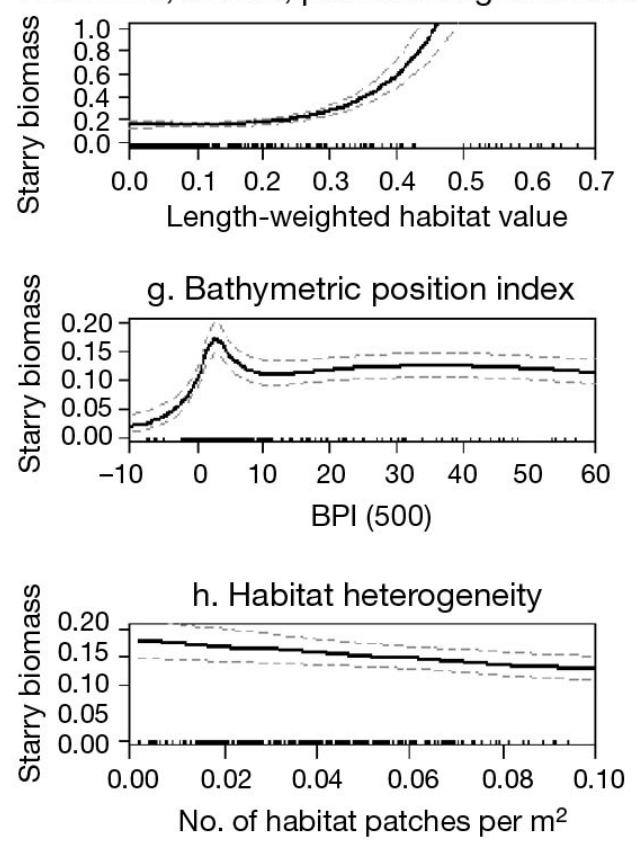

Fig. 6. Sebastes constellatus. Response curves, based on habitat co-variables from visual surveys and acoustic multibeam bathymetry, for generalized additive model (GAM) predicted density versus (a) depth, (b) length-weighted habitat values in high-relief rock (Lhard) and (c) length-weighted habitat values in low-relief rock (Mhard); and GAM-predicted biomass versus (d) depth, (e) length-weighted habitat values in Lhard, (f) length-weighted habitat values in Mhard, (g) bathymetric position index $(\mathrm{BPI})$, and $(\mathrm{h})$ habitat heterogeneity. Solid lines $=$ mean $( \pm 1 \mathrm{SE}$, dashed lines $)$. Rug plots along the $x$-axis $=$ calibration data points

(LiDAR) contributed most to the spatial model of habitat suitability for Stegastes planifrons (threespot damselfish). Habitat complexity, particularly the slope of the slope (a measure of the maximum rate of slope change) was found to be the most useful predictor of diversity and abundance of fishes and corals in the Caribbean (Pittman et al. 2009).

Many rockfish species demonstrate habitat preferences for complex rocky substrata (Love \& Yoklavich 2006, Love et al. 2009). Young et al. (2010) applied generalized linear models to predict the highest probability of occurrence (presence/absence) of Sebastes rosaceus in high relief rocky areas of Cordell Bank on California's northern coast, with habitat complexity included as a strong predictor in these models. We found densities of $S$. rosaceus and S. constellatus to have similar patterns of habitat affinity in relation to fine-scale remotely sensed measures of habitat complexity. We also found that intermediate levels of habitat heterogeneity were important in explaining $S$. rosaceus variability across the seascape and to demonstrate the importance of composition 


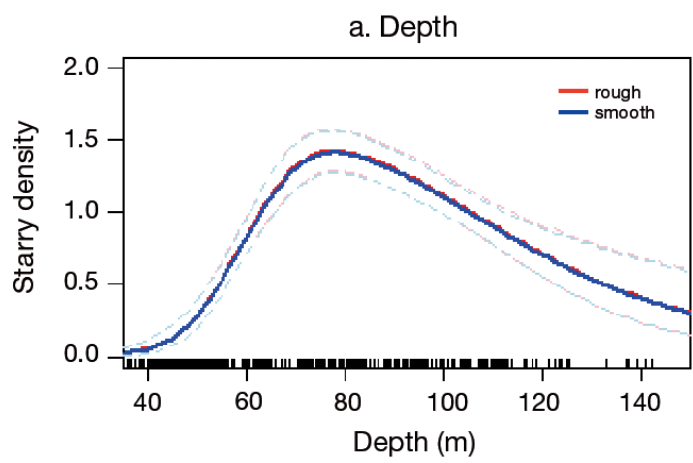

b. Bathymetric position index

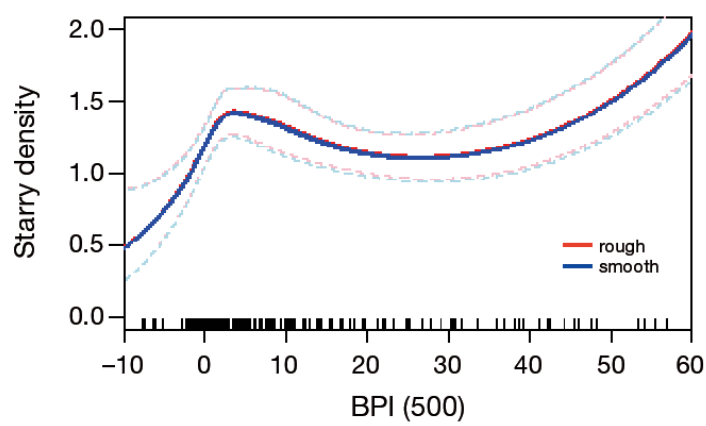

Fig. 7. Sebastes constellatus. Response curves, based on habitat co-variables derived from acoustic multibeam bathymetric surveys, for generalized additive model (GAM) predicted density versus (a) depth and (b) bathymetric position index (BPI); and GAM-predicted biomass versus (c) depth, (d) BPI, and (e) habitat complexity with factor representing rough substratum (red lines) and smooth substratum (blue lines). Solid lines $=$ mean $( \pm 1 \mathrm{SE}$, dashed lines $)$. Rug plots along the $x$-axis $=$ calibration data points

and configuration of habitat features. Further, the BPI co-variable highlights areas in the seascape that are tops of large pinnacles or rocky outcrop features adjacent to canyons (e.g. Point Pinos and Point Sur). Anderson \& Yoklavich (2007) reported S. rosaceus rockfishes were found in groups of other largebodied rockfishes (e.g. S. paucispinis, S. flavidus, $S$. rubrivinctus, and Sebastomus spp.) with strong associations to high-relief rocky outcrops. In addition to the refuge provided by structurally complex habitat, relatively productive waters associated with rocky pinnacles and outcrops in and adjacent to canyons could support greater fish biomass.

The visual survey methods used in this study can be more effective than extractive trawl surveys in estimating abundance of rockfish species living in high-relief rocky areas. As with all survey methods, there are several assumptions and sources of uncertainty associated with visual surveys. We have criti-
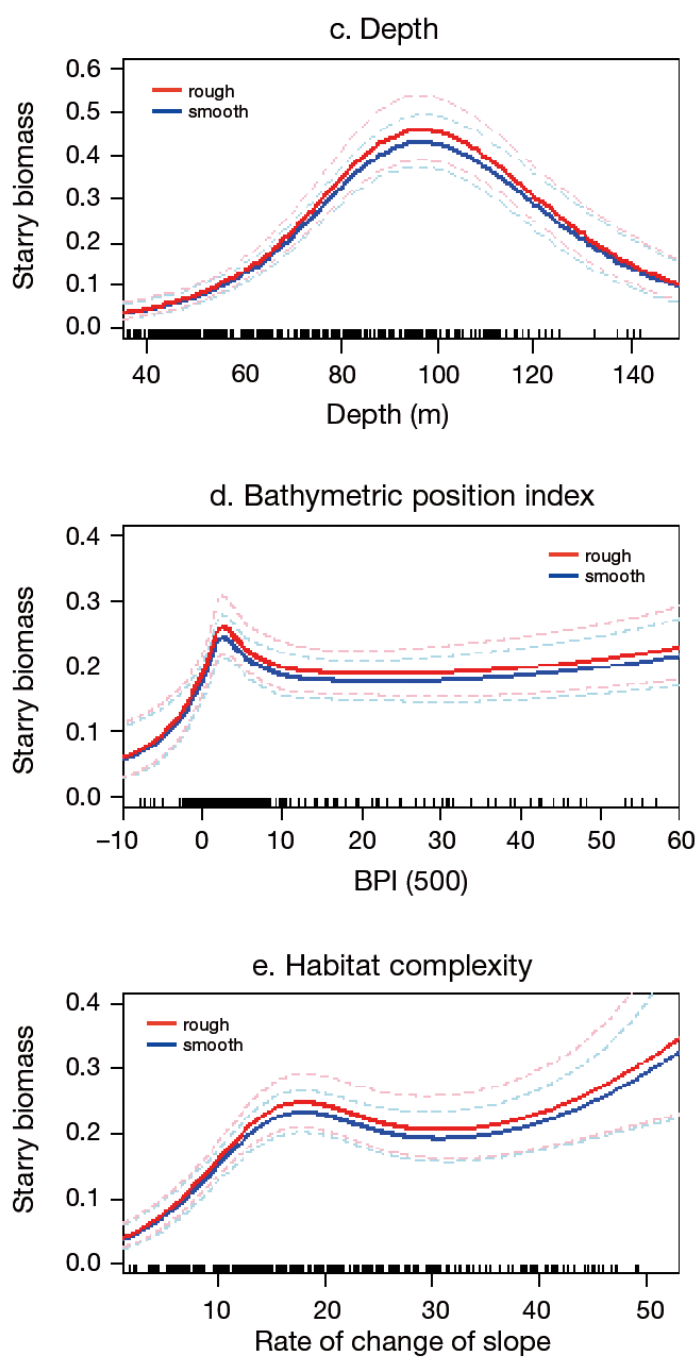

cally evaluated several of these assumptions using similar survey techniques in prior field surveys (Yoklavich et al. 2007, Laidig et al. 2013). The strip transect method used in our study assumes $100 \%$ detection of the target species within the strip. To help meet this assumption, we used a relatively narrow strip width $(2 \mathrm{~m})$ during our surveys. That said, it is unlikely that $100 \%$ of $S$. rosaceus and S. constellatus were seen in the transects, particularly the smallest individuals nestled in the rocky substrata. This would result in an underestimation of densities by some unknown amount. Additional studies will be required to estimate true detectability of these species in high-relief habitats.

Another important assumption of these underwater surveys is that rockfish behavior is independent of the observer and submersible (i.e. no avoidance or attraction). Laidig et al. (2013) reported that 6 and $10 \%$ of $S$. rosaceus near (total $\mathrm{n}=134)$ and on $(\mathrm{n}=10)$ 
the seafloor, respectively, reacted mostly by swimming toward or to the left of the Delta submersible during surveys off central California. Sebastes constellatus reacted similarly, with 5 and $8 \%$ of fish near $(\mathrm{n}=21)$ and on $(\mathrm{n}=13)$ the seafloor responding to the survey vehicle ${ }^{2}$. Both species moved an average distance of 2 to $3 \mathrm{~m}$ per reaction. This type of reaction could bias estimated densities if the fish entered or exited the strip transect; otherwise, these relatively small movements would not influence the resultant densities. In addition, the assumption that the fish are distributed randomly with respect to the transect was met by randomizing survey sites and traversing haphazardly across substratum types and depth gradients within designated rocky habitats.

There also are potential sources of error related to fish measurements. In an earlier study (Yoklavich et al. 2007), we estimated error associated with our underwater estimates of fish size. From the submersible we measured fish replicas of known total length, and size generally was underestimated by a relatively small amount (mean \pm SD deviation: $-1.1 \pm$ $1.2 \mathrm{~cm}$ ). This would result in an underestimate of biomass. Biomass estimates also contain some unknown amount of error related to the conversion of length to weight. However, the regression of weight and length (Love et al. 1990) provided an excellent fit for both of our target species, so the amount of error introduced using length to calculate weight is expected to be small.

Further, our research is limited by the temporal and spatial extent of the study. Our visual surveys were conducted only in Fall (September to November) of 2007-2008, and we did not expect a seasonal effect in abundance because these sedentary rockfish species are not known to be wide-ranging (Love et al. 2002). However, repeating these surveys to establish time series in density and biomass over several years would allow us to evaluate change in rockfish abundance across the region as well as inside and outside marine protected areas (MPA). In particular, this study represents a baseline for monitoring the deepwater portion of 8 MPAs that were established on the central coast coincident with the commencement of our surveys in September 2007. With future monitoring, we will be able to include an MPA term in the models to evaluate the efficacy of these closed areas in protecting deep-water species of rockfishes. The

${ }^{2}$ Pers. comm., T. Laidig, Fisheries Ecology Division, Southwest Fisheries Science Center, NOAA, 110 Shaffer Rd., Santa Cruz, CA 95060, USA geographic scale of our study could also be expanded to include data from our visual surveys in rocky areas of southern California where both target species are common.

We developed 2 sets of models in this study: one set based on co-variables from both the visual surveys and region-wide high-resolution bathymetry and the other set of models based only on co-variables derived from the bathymetry. Our motivation was to examine the added value of data collected in situ from a submersible compared to that collected solely from acoustic surveys. The models using all of the covariates (including those from the visual surveys) accounted for more of the overall variance (42 to $54 \%$ ) in estimated density and biomass for both species than those using only derived variables from multibeam bathymetry (29 to $38 \%$ ). Clearly data from the visual surveys improved the predictive capabilities of the models. However, in order to apply predictions on a region-wide scale, only the bathymetric co-variates could be used because in situ data were not available on a broad scale.

Benthic terrain analysis of multibeam bathymetric acoustic data is a valuable way to identify seafloor habitat that supports individual species and assemblages (Wilson et al. 2007, Guinan et al. 2009). Quantifying and mapping elements of rockfish habitat, such as seafloor substratum type, texture, and complexity, are critical for evaluating the effectiveness of these areas to maintain rockfish stocks (Yoklavich et al. 2000, 2007). Our ability to derive indices of benthic habitats (e.g. habitat complexity, depth, BPI) from multibeam acoustic data ${ }^{\frac{3,4}{4}}$ that were recently synthesized across California state waters supports the production of spatially predictive maps of demersal fish populations at a regional scale relevant to the assessment of fish stocks in rebuilding status. Further, providing a spatial component to these predictions can be critical in the management of relatively sedentary rockfish species to safeguard against local depletion (Parker et al. 2000).

Currently it is challenging to integrate oceanographic and benthic habitat predictor variables into habitat models and maps, largely because the spatial resolution of available oceanographic data (e.g. temperature, salinity, and bottom currents from regional oceanographic modeling systems [ROMS]) is 10s of $\mathrm{km}$, and the resolution of the benthic habitat data is several orders of magnitude greater $(<1 \mathrm{~m}$ from

\footnotetext{
3http://walrus.wr.usgs.gov/mapping/csmp/ ${ }^{4} \mathrm{http}$ ://seafloor.otterlabs.org/csmp/csmp.html
} 
visual surveys and 2-5 $\mathrm{m}$ from multibeam acoustic surveys of bathymetry). Our models were developed only with benthic habitat predictors. However, the inclusion of oceanographic variables could further improve the predictive capability of our models and maps when these data become available at finer spatial scales.

Rockfishes are among the most valuable fisheries in California, have extremely vulnerable life-history characteristics, and cannot sustain levels of fishing mortality; as a result, they are being managed more conservatively than in the past. The predictive maps of density and biomass of $S$. rosaceus and $S$. constellatus will improve our understanding of habitat variables that influence the spatial distribution and abundance of these species across the central coast. The results of our study provide information to support stock assessments of these 2 species of rockfishes, both considered to be data-poor species by the PFMC. For example, using our predictive maps of biomass, stock assessors could estimate total biomass (and associated uncertainty) of these species within our designated study area off central California and consider those estimates in context with assessments based solely on commercial and recreational landings (Dick \& MacCall 2010, Ralston et al. 2010). Such estimates of habitat-specific abundance are critical to effectively control the magnitude of fishing mortality and to support the local recovery of depleted populations.

\section{CONCLUSIONS}

In this study we developed models of rockfish density and biomass based on in situ observations of fish numbers, size, and associated seafloor substratum variables and derived variables from region-wide multibeam bathymetry. Model results were expressed as predictive maps of density and biomass on a regional scale. Such maps allow us to quantify habitat capacity, prioritize habitat conservation, and evaluate potential risk of various human activities to rockfish populations over broad spatial scales. These results have direct application to coastal and marine spatial management, particularly in (1) the design and monitoring of MPAs, (2) improving the identification of essential fish habitats, (3) distinguishing those areas important to the restoration or rebuilding of depleted stocks, and (4) advancing our understanding of the effects of a changing climate on the spatial distribution and abundance of Pacific coast groundfishes.
Acknowledgements. We thank R. Starr, T. Laidig, M. Love, M. Nishimoto, L. Snook and others for help with field data collection. We are especially grateful to T. Laidig for postcruise video analysis and to D. Watters for database management. We thank D. Huff for his expertise and help with data analyses. J. Blakley assisted with derived seafloor indices. The in situ visual survey data were collected as part of a grant from the California Ocean Protection Council to R. Starr and M.M.Y., and the analytical work was supported by a grant from NOAA NMFS Habitat Assessment Improvement Plan Program to M.M.Y. Acoustic data used in this study were acquired, processed, archived, and distributed by the Seafloor Mapping Lab of California State University Monterey Bay, supported in part by California State Mapping Program. We appreciate the very thoughtful and useful comments and suggestions from E. J. Dick, D. Huff, S. Sogard, and 3 anonymous reviewers.

\section{LITERATURE CITED}

Anderson TJ, Yoklavich MM (2007) Multiscale habitat associations of deepwater demersal fishes off central California. Fish Bull 105:168-179

Anderson TJ, Syms C, Roberts DA, Howard DF (2009) Multiscale fish-habitat associations and the use of habitat surrogates to predict the organization and abundance of deepwater fish assemblages. J Exp Mar Biol Ecol 379:34-42

Barto K (2011) MuMl package: multi-model inference. www.cran.r-project.org/web/packages/

Burnham KP, Anderson DR (2002) Model selection and multimodel inference, 2nd edn. Springer-Verlag, New York, NY

Costa B, Taylor JC, Kracker L, Battista T, Pittman S (2014) Mapping reef fish and the seascape: using acoustics and spatial modeling to guide coastal management. PLoS ONE 9:e85555

Dick EJ, MacCall AD (2010) Estimates of sustainable yield for 50 data-poor stocks in the Pacific coast groundfish fishery management plan. NOAA Tech Memo NOAATM-NM FS-SWFSC-460

Eittreim SL, Anima RJ, Stevenson AJ, Wong FL (2000) Seafloor rocks and sediments of the continental shelf from Monterey Bay to Point Sur, California. USGS Miscellaneous Field Studies Map MF-2345, online v1.0. http://pubs.usgs.gov/mf/2000/2345/

- Greene HG, Yoklavich MM, Starr RM, O'Connell VM and others (1999) A classification scheme for deep seafloor habitats. Oceanol Acta 22:663-678

Guinan J, Brown C, Dolan MF, Grehan AJ (2009) Ecological niche modelling of the distribution of cold-water coral habitat using underwater remote sensing data. Ecol Inform 4:83-92

Hastie T, Tibshirani R, Friedman JH (2009) The elements of statistical learning: data mining, inference, and prediction. Springer series in statistics. Springer, New York, NY

Hickey BM (1998) Coastal oceanography of western North America from the tip of Baja California to Vancouver Island. In: Robinson AR \& Brink KH (eds) The Sea, Vol 11. The global coastal ocean: processes and methods. John Wiley \& Sons, New York, NY, p 345-393

Iampietro PJ, Young MA, Kvitek RG (2008) Multivariate prediction of rockfish habitat suitability in Cordell Bank National Marine Sanctuary and Del Monte Shalebeds, California, USA. Mar Geod 31:359-371 
Laidig TE, Watters DL, Yoklavich MM (2009) Demersal fish and habitat associations from visual surveys on the central California shelf. Estuar Coast Shelf Sci 83:629-637

Laidig TE, Krigsman LM, Yoklavich MM (2013) Reactions of fishes to two underwater survey tools, a manned submersible and a remotely operated vehicle. Fish Bull 111: $54-67$

Levin PS, Schwing FB (eds) (2011) Technical background for an integrated ecosystem assessment of the California Current: groundfish, salmon, green sturgeon, and ecosystem health. US Dep Commer NOAA Tech Memo NMFS-NWFSC-109

Love MS (2006) Subsistence, commercial, and recreational fisheries. In: Allen LG, Pondella DJ, Horn MH (eds) The ecology of marine fishes: California and adjacent waters. University of California Press, Berkeley, CA, p 567-594

Love MS (2011) Certainly more than you want to know about the fishes of the Pacific coast. Really Big Press, Santa Barbara, CA

Love MS, Yoklavich M (2006) Deep rock habitats. In: Allen LG, Pondella DJ, Horn MH (eds) The ecology of marine fishes: California and adjacent waters. University of California Press, Berkeley, CA, p 253-266

Love MS, Morris P, McCrae M, Collins R (1990) Life history aspects of 19 rockfish species (Scorpaenidae: Sebastes) from the Southern California Bight. NOAA Tech Rep NMFS-87

Love MS, Yoklavich M, Thorsteinson L (2002) The rockfishes of the Northeast Pacific. University of California Press, Berkeley, CA

Love MS, Yoklavich M, Schroeder DM (2009) Demersal fish assemblages in the Southern California Bight based on visual surveys in deep water. Environ Biol Fishes 84: $55-68$

Lundblad ER, Wright DJ, Miller J, Larkin EM and others (2006) A benthic terrain classification scheme for American Samoa. Mar Geod 29:89-111

Miller RR, Field JC, Santora JA, Schroeder ID and others (2014) A spatially distinct history of the development of California groundfish fisheries. PLoS ONE 9:e99758

Montgomery DC, Peck EA (1992) Introduction to linear regression analysis, 2nd edn, Probability and Statistics Series. John Wiley \& Sons, New York, NY

Moore CH, Harvey ES, Van Neil K (2010) The application of predicted habitat models to investigate the spatial ecology of demersal fish assemblages. Mar Biol 157: 2717-2729

O'Farrell MR, Yoklavich MM, Love MS (2009) Assessment of habitat and predator effects on dwarf rockfishes (Sebastes spp) using multi model inference. Environ Biol Fishes 85:239-250

Parker SJ, Berkeley SA, Golden JT, Gunderson DR and others (2000) Management of Pacific rockfish. Fisheries 25: 22-30

PFMC (Pacific Fishery Management Council) (2011) Pacific coast groundfish fishery management plan for the California, Oregon, and Washington groundfish fishery. PFMC, Portland, OR. www.pcouncil.org/groundfish/ fishery-management-plan/

Pinheiro JC, Bates DM (2009) Mixed-effects models in S and

Editorial responsibility: Jake Rice,

Ottawa, Ontario, Canada
S-PLUS. Springer Verlag, New York, NY

Pittman SJ, Brown KA (2011) Multi-scale approach for predicting fish species distributions across coral reef seascapes. PLoS ONE 6:e20583

Pittman SJ, Costa BM, Battista TA (2009) Using lidar bathymetry and boosted regression trees to predict the diversity and abundance of fish and corals. J Coast Res (Spec Issue) 53:27-38

Punt A, Ralston S (eds) (2007) A management strategy evaluation of rebuilding revision rules for overfished rockfish stocks. Alaska Sea Grant College Program, AK-SG-07-01

R Development Core Team (2011), R: a language and environment for statistical computing. The R Foundation for Statistical Computing, Vienna. www.r-project.org

Ralston S, MacFarlane BR (2010) Population estimation of bocaccio (Sebastes paucispinis) based on larval production. Can J Fish Aquat Sci 67:1005-1020

Ralston S, Pearson DE, Field JC, Key M (2010) Documentation of the California catch reconstruction project. NOAA Tech Memo NOAA-TM-NMFS-SWFSC-461

Roberts JJ, Best BD, Dunn DC, Treml EA, Halpin PN (2010) Marine Geospatial Ecology Tools: an integrated framework for ecological geoprocessing with ArcGIS, Python, R, MATLAB, and C++. Environ Model Softw 25: 1197-1207

Wilson MF, O'Connell B, Brown C, Guinan JC, Grehan AJ (2007) Multiscale terrain analysis of multibeam bathymetry data for habitat mapping on the continental slope. Mar Geod 30:3-35

> Wood SN (2004) Stable and efficient multiple smoothing parameter estimation for generalized additive models. J Am Stat Assoc 99:673-686

Yoklavich M, Starr R, Steger J, Greene HG, Schwing F, Malzone C (1997) Mapping benthic habitats and ocean currents in the vicinity of central California's Big Creek Ecological Reserve. NOAA Tech Memo, NOAA-TMNMFS-SWFSC-245

Yoklavich MM, Greene HG, Cailliet GM, Sullivan DE, Lea RN, Love MS (2000) Habitat associations of deep-water rockfishes in a submarine canyon: an example of a natural refuge. Fish Bull 98:625-641

Yoklavich MM, Cailliet GM, Lea RN, Greene HG, Starr R, DeMarignac J, Field J (2002) Deepwater habitat and fish resources associated with the Big Creek Marine Ecological Reserve. CCOFI Rep 43:120-140

Yoklavich MM, Love MS, Forney KA (2007) A fisheryindependent assessment of an overfished rockfish stock, cowcod (Sebastes levis), using direct observations from an occupied submersible. Can J Fish Aquat Sci 64: 1795-1804

> Young MA, Iampietro PJ, Kvitek RG, Garza CD (2010) Multivariate bathymetry-derived generalized linear model accurately predicts rockfish distribution on Cordell Bank, California, USA. Mar Ecol Prog Ser 415:247-261

Zuur A, Ieno EN, Walker N, Saveliev AA, Smith GM (2009) Mixed effects models and extensions in ecology with R. Springer, New York, NY

Zuur AF, Ieno EN, Elphick C (2010) A protocol for data exploration to avoid common statistical problems. Methods Ecol Evol 1:3-14

Submitted: February 5, 2015; Accepted: July 28, 2015

Proofs received from author(s): November 12, 2015 